\title{
Psychological Electoral Neighbourhood Effects
}

\author{
James Ackland, Andrés Gvirtz, Jason Rentfrow, Lee de-Wit
}

December 6, 2021

\begin{abstract}
Using combined data from the British Election Study, British Social Attitudes Survey, Census, and the Cambridge Personality and Social Dynamics Research Group, a preregistered large-n regression design demonstrates the continued presence of neighbourhood effects in British elections. In addition to conventional demographic approaches, neighbourhood effects of personality dimensions and ideological orientations are demonstrated. For example, living in an area high on Right-Wing Authoritarianism (RWA) is positively associated with one's likelihood of voting Conservative, regardless of one's own RWA. These findings are consistent with models in which aggregate psychological phenomena influence individual decision making, either in elections, or in domestic migration preferences. The research furthers the integration of social psychological theory with electoral analysis, but further work is required to understand the causal mechanism behind neighbourhood effects.
\end{abstract}

\section{Introduction}

A primary shared goal of political science and political psychology is to further our understanding of why individuals choose to vote the way they do. Recent narratives around the political landscape increasingly consider the role of context for voters, from the supposed cluster of 'Red Wall' constituencies to the transmission of (mis)information through social networks. The present research attempts to quantify geographic contextual influences by addressing an important, but often neglected, factor in voting behaviour.

'Neighbourhood effects', under which an individual's decision making is influenced by the characteristics of the place they live, have been successfully applied to electoral contexts, but remain unintegrated with the political psychology literature.

Generally speaking, political psychology attempts to explain voting by placing a premium on measures of disposition, personality, motivation, and ideological orientation, which routinely outperform demographic predictors (Zmigrod et al., 2021). Yet, this approach necessarily centralises the individual in the decision-making process, and therefore risks failing to consider exogenous influences like neighbourhood. Indeed, no previous psychological work exists on electoral neighbourhood effects. 
The present research attempts to redress this gap in the literature, by considering the political psychology of neighbourhood effects in modern British elections.

\subsection{The Neighbourhood Effect in British Elections}

Miller (1978) defines the electoral neighbourhood effect as: "the power of the environment to structure social contacts plus the empirical fact (and it is only empirical, not logical) that contact... makes a consensual impact on partisan choice". In its simplest form, Miller's neighbourhood effect is the claim that a 'natural supporter' of party A will be more likely to be dissuaded from this preference if the majority of their neighbours are supporters of party B. This dynamic of influence from proximal peers has the emergent properties of local consensus and global polarisation (i.e. spatial clustering) of voting behaviour. This initial analysis focuses on social class as the determinant of political preference, demonstrating that working-class individuals in middle-class constituencies are more likely to vote Conservative than those in working-class constituencies, and vice versa (Miller, 1977).

With access to higher-resolution geographical data, researchers can construct 'bespoke neighbourhoods' ${ }^{1}$ to characterise a respondent's neighbours, for example by their average social class. With this method, a strong correlation is shown between the likelihood of a person voting Conservative and the social class of their immediate neighbours. And this effect is seen between individuals of the same social class, but living in neighbourhood of varying social class. This effect is detected for the 1997 election at each of six sizes of 'bespoke neighbourhood' (Macallister et al., 2001).

Qualitative (Olivas Osuna, Kiefel, and Gartzou Katsouyanni, 2021), distributionfitting (Upton and Stray, 1986) and agent-based (Braha and De Aguiar, 2017) approaches have provided convergent evidence. Further strong evidence is presented by Johnston, Propper, Sarker, et al. (2005) using a nested logistic regression approach which can control for multiple known predictors of voting behaviour. This method is adopted widely in the literature (e.g. Harrop, Heath, and Openshaw, 1991; Johnston, Jones, et al., 2004; Johnston, Propper, Burgess, et al., 2005), and in the present research.

\subsection{The Mechanism and Nature of the Neighbourhood Ef- fect}

Despite the strong evidence for the existence of a neighbourhood effect in elections prior to 2001, uncertainty remains about the mechanism by which it operates. Two mechanisms are dominant in the literature: 'conversion by conversation' and 'ideological migration'.

In 'conversion by conversation', voters come into contact with their neighbours, and gradually update their own political beliefs in line with local social

\footnotetext{
${ }^{1}$ Geographic units of a researcher-defined size, but usually smaller than constituencies, and personalised around the postcode of each survey respondent.
} 
norms by a process of social conformity (Miller, 1978). Because neighbourhoods are heterogeneous, the same person would be subject to different social pressures in different places, leading to divergent voting behaviours. Johnston, Propper, Sarker, et al. (2005) reason that, under this mechanism, neighbourhood effects on individuals have two prerequisites: i) connectedness with, and ii) positive affect towards, one's neighbourhood. These are measured in their 'neighbourhood social capital' scale, drawing on Putnam (2001), which they find to moderate the size of neighbourhood effects on individuals.

Alternatively, ideological migration describes a situation in which individuals are more likely to move to neighbourhoods occupied by similar individuals. This similarity might be explicitly in terms of political affiliation, but migration could also be based on any number of other dimensions that correlate with voting behaviour, including preferences for ostensibly apolitical neighbourhood features (Motyl, Prims, and Iyer, 2020). In this case, a neighbourhood effect might be observed because someone who votes 'incongrously' (e.g. a middleclass, white, Labour voter) might be drawn to a Labour-voting area with more conventionally Labour-voting characteristics. Without knowledge of migration, it would appear that the neighbourhood persuaded the would-be Conservative to vote Labour, but in fact, the causality is reversed - the individual's affinity for Labour (perhaps indirectly) caused them to move to the pro-Labour neighbourhood in question. Notably, Schelling (1971) demonstrates that only a small individual migration preference for homogeneity is necessary for the emergent property of widespread segregation.

The likelihood of each of these mechanisms can be challenged at face. Dunleavy (1980) questions if we can really "assume that political alignment brushes off on people by rubbing shoulders in the street", while critics of ideological migration might doubt whether political affiliation can really override more obvious preferences, such as employment, in migration decisions. Yet it seems that at least one of these mechanisms, or perhaps both in tandem, is required to generate the effects seen in the prior literature.

Regardless, the lack of clarity around the mechanism requires that researchers differentiate between findings that support neighbourhood effects as a statistical fact that might predict future outcomes; and those that support conclusions about the process of individual electoral decision-making. The findings in the present research fall almost exclusively into the former category.

\subsection{The Case for Further Neighbourhood Effects Research in Psychology}

The descriptive evidence base for neighbourhood effects has accumulated to the extent that their existence in British elections in the late $20^{\text {th }}$ century is now hard to doubt. But Johnston, Jones, et al. (2004) demonstrate variability in the strength of the neighbourhood effect over time, such that it is possible that these effects have not persisted into the $21^{\text {st }}$ century. Indeed, the rise of online social networks might plausibly have universally reduced neighbourhood social capital, thus replacing geographical space with cyberspace as the location for social 
influences on voting behaviour. Furthermore, much of the existing literature is limited by the domination of demographics, and particularly social class, as the chief variable characterising both individuals and constituencies, yet YouGov's post-election survey from 2019 shows a near identical distribution of votes by class for the two major parties (McDonnell and Curtis, 2019). The present research, therefore, seeks to update the literature with analysis of more recent elections, as well as with more recent understandings of the factors underlying voting behaviour.

The field of political psychology has enjoyed success in modelling individual voting behaviour with cognitive and personality variables over and above traditional demographics (Zmigrod et al., 2021). Bale et al. (2020) highlight the dominant role of social and economic 'values', in post-Brexit UK electoral politics. If the bases of individual voting behaviour have moved from social class to a broader definition of identity, and now to values and personality, then it is reasonable to hypothesise that the important characteristics of a neighbourhood have followed the same trajectory.

While the mechanism of the neighbourhood effect remains poorly understood, neither of the mechanisms proposed in Section 1.2 excludes the possibility of psychological neighbourhood effects. Valid psychological information about others can be acquired through conversation, or even by observation (Borkenau and Liebler, 1993), allowing a social interaction mechanism. Yet personality is also a factor in intention to migrate (Jokela, 2009), which should lead to a situation in which the 'churn-rate' of a neighbourhood is correlated with the average personality traits of its inhabitants.

The hypotheses in this paper test non-social-class characteristics in neighbourhood effect studies, including psychological predictors of voting behaviour. We also test for the existence of neighbourhood effects in recent elections where such effects are yet to be demonstrated.

\subsection{Personality Traits}

Recent empirical work has demonstrated the importance of personality in shaping various economic, social and health outcomes (Peter J Rentfrow, 2020; Obschonka et al., 2018; Jokela, 2009; Oishi, Kohlbacher, and Choi, 2018). Further, previous work has highlighted the associations between regional personality and aggregate vote shares in the UK (Peter J. Rentfrow, Jokela, and Lamb, 2015).

Personality traits are not uniformly distributed across the UK. This spatial heterogeneity is a prerequisite for a neighbourhood effect - gender, for example, cannot cause a neighbourhood effect, because there is almost no variation in the gender distributions of constituencies $(\mathrm{M}=49.4 \%$ Male, $\mathrm{SD}=0.97 \%)$. Of the Big Five, Openness and Conscientiousness are particularly well distributed (Openness ICC $=.93$, Moran's $I=.56$, Conscientiousness ICC $=.86$, Moran's $I=.43$ ), suggesting substantial clustering of areas similar on these measures Peter J. Rentfrow, Jokela, and Lamb (2015).

\footnotetext{
${ }^{2}$ beliefs falling short of policy preferences, but more specific than moral foundations
} 
It is, therefore, reasonable to hypothesise that aggregate personality is a characteristic of neighbourhoods that generates a neighbourhood effect. At the individual level, research associating the Big Five personality traits with political preference is widespread, with the major conclusion that high Openness predicts left-leaning voting, while high Conscientiousness predicts right-leaning voting (e.g. Greaves, Robertson, and Cowie, 2017; Gerber et al., 2011). While the remaining three traits (Agreeableness, Neuroticism and Extraversion) are also often considered, they are rarely as useful in the prediction of voting behaviour as are Openness and Conscientiousness. In the UK context, Aidt and Rauh (2018) use longitudinal voting behaviour data to isolate the 'stable' part of partisanship - distinct from temporary changes in allegiance that might arise from current affairs or economic conditions. In line with results from US samples, they find Conscientiousness and Openness to be the strongest correlates of partisanship across multiple parties.

This, combined with their greater within-unit homogeneity than other traits, makes Openness and Conscientiousness particularly strong candidates for geographical political psychology research.

\subsection{Ideological Orientations}

Duckitt and C. G. Sibley (2009) argue that personality traits are cognitive precursors to what might be termed 'ideological orientations' (Zmigrod et al., 2021). These orientations sit somewhere between cognitive processes and expressions of political belief, similar to the 'values' framework proposed by Bale et al. (2020).

Both Right-Wing Authoritarianism (RWA) and Social Dominance Orientation (SDO) have been postulated as such orientations that might precede a range of political beliefs and behaviours (Duckitt and C. G. Sibley, 2009), perhaps even with an evolutionary basis (Claessens et al., 2020). RWA refers to the preference for social conformity, with those high in RWA generally viewing the world as dangerous C. Sibley and Duckitt (2009). In contrast, SDO is high in those who see the world as competitive, and therefore hold a preference for meritocratic beliefs and dominance hierarchies that support inequality (Ho et al., 2015; Pratto et al., 1994).

An extensive and growing literature links these measures to electoral choice at the individual level (Van Hiel and Mervielde, 2002; Mutz, 2018; Cornelis and Van Hiel, 2015; Golec de Zavala, Guerra, and Simão, 2017; Satherley, C. G. Sibley, and Osborne, 2021; Laustsen, Petersen, and Klofstad, 2015; Kleppest $\varnothing$ et al., 2019). However, to the best of our knowledge, neither measure has been the subject of geographical psychological investigation in the UK, and so prior to this work it is unknown whether there is substantial variation in their spatial distribution. The existence of spatial variation in ideological orientations must therefore be established before these measures can be tested as neighbourhood effects. 


\subsection{Overview of the Research Programme}

Using a series of large-n models, this research seeks to test three important claims for the progression of the neighbourhood effects literature. First, whether electoral neighbourhood effects, last tested in the 2001 election, persist in the UK. Second, whether there are neighbourhood effects for psychological phenomena that strongly predict voting at the individual level, and third, whether there are psychological moderators of the neighbourhood effect.

\section{Hypotheses}

We test four preregistered hypotheses with the aim to replicate and extend research on neighbourhood effects in political psychology.

H1 There is a demographic neighbourhood effect in British elections, under which individuals are influenced by the characteristics of their local area when voting. Additional variance in voting behaviour can be explained by considering the neighbourhood average of the following demographic variables in voting models:

H1a Age

H1b Education

H1c Social Class

H1d Employment Status

H1e Ethnicity

H2 There is a psychological neighbourhood effect in British elections, under which individuals are influenced by the characteristics of their local area when voting. Additional variance in voting behaviour can be explained by considering the neighbourhood average of the following demographic variables in voting models:

H2a Right-wing Authoritarianism

H2b Social Dominance Orientation

H2c Conscientiousness

H2d Openness

H3 The psychological neighbourhood effects (identified under H2), will explain additional variance in voting behaviour to demographic neighbourhood effects (identified under H1).

H4 The propensity to be affected by one's neighbourhood characteristics (demographic or psychological) is itself a psychological process, moderated by the following traits.

H4a Extraversion 


\author{
H4b Social Trust \\ H4c Voting Norms \\ H4d Neighbourhood Social Capital
}

\title{
3 Methodology
}

Our methodology followed the preregistration hosted on the Open Science Framework, see Appendix 1 for further details.

\subsection{Dependent Variable}

The best operationalisation of voting behaviour is a matter of debate, especially in UK General Elections, where there is a recognised duopoly, but many parties attract non-trivial vote shares. Miller (1978) describes the dominant operationalisation strategies as either unipolar, 'the respondent either voted for party $\mathrm{x}$, or did not', or bipolar 'the respondent either voted for party $\mathrm{x}$, or party $y$, or is removed from the analysis'. Neither of these strategies represents a good dichotomisation of electoral choice, but the alternatives are either unsuitable or worse. Therefore, we settle on three binary dependent variables:

1. Labour against Conservative (bipolar)

2. Labour against not-Labour, including abstention (unipolar)

3. Conservative against not-Conservative, including abstention (unipolar)

While variables referring to non-major parties such as the Liberal Democrats, the SNP, or abstention ${ }^{3}$ were considered, they were ultimately rejected on the grounds of parsimony and sample size, which rapidly deteriorates when minor parties are considered.

\section{$3.2 \quad$ Individual-level Data}

To test our hypotheses, we require a large database of individuals with data covering, at minimum, a voting history, a location of residence, and the demographic and psychological data of interest. Several datasets were considered, with the British Election Study (hereafter: BES), and the British Social Attitudes Survey (hereafter: BSA) meeting these criteria. Data from multiple waves of each of these surveys were combined using R (R Core Team, 2020) into a single "super-sample"(Hoover and Dehghani, 2020), comprising over 100,000 individuals, some of whom report their voting behaviour in more than one election. Data availability from these sources provides voting histories in every general election from 1992 to 2019, as well as votes in the Brexit referendum. Details of the measurement and inclusion justification for all independent variables are reported in the Supplementary Material.

\footnotetext{
${ }^{3}$ See Section 6.2 for a fuller discussion.
} 


\subsection{Weighting of Individual-level Data}

Following Solon, Haider, and Wooldridge (2015) and Jerrim et al. (2017) we take the approach that weighting is only necessary where the variables determining selection probability are not included amongst the independent variables of a model. "Where the survey organization provides sampling weights to adjust for differential nonresponse, including attrition from a panel survey, and these weights are based only on observable characteristics that are controlled for in the regression model (perhaps gender, race, age, location)... it is not clear that there is an advantage to using such weights" (Solon, Haider, and Wooldridge, 2015). Our models employ a range of demographic predictors often associated with sample weighting (gender, age, education, political attention etc.), such that it is likely that most, if not all, of the variables in the weighting formulae used by the BES and BSA are controlled for within our analysis ${ }^{4}$.

We do, however, apply weights to account for endogenous sampling and sampling bias introduced by the use of Postcode Address Files.

To account for endogenous sampling, we compare the sample dependent variable distribution to the election results. In all elections studied, the sample distribution is significantly different from the population distribution (as determined by a chi-square test), and of substantial size (see Section 3.7).

When samples are based on a postcode address file (PAF), people living in larger households or at shared addresses are less likely to be sampled. This is the case for the 1997-2002 waves of the BES, and for every wave of the BSA other than the first. Unfortunately, weights to counteract this are unavailable for the BES, but they are calculated for the BSA and are therefore applied to models. These weights are based purely on household size, so do not overlap with variables included in our models ${ }^{5}$.

\subsection{Constituency-level Data}

Constituency-level data is required to provide characterisations of the neighbourhoods in which each participant lives. This data is acquired from three sources: the 2011 Census, a supplementary dataset provided by the Cambridge Personality and Social Dynamics Research Group (hereafter: 'PSD data'), and aggregation of the BES and BSA participants.

\subsubsection{Census}

As a total population sample, the census data is considered to be close to the 'ground truth'. The included variables mirror the demographics used at the individual level, except for gender, which has so little variance across units as to be a self-evidently unhelpful predictor at this scale.

\footnotetext{
${ }^{4}$ Unfortunately, neither organisation publishes its weighting strategy in full, so we cannot be certain of the contents of the discarded weights.

${ }^{5}$ They are not what the BSA refers to as 'calibration weights', which do consider demographics
} 


\subsubsection{PSD Data}

Unfortunately, the census does not collect data on psychological phenomena. Therefore, mean values for our psychological variables were inferred from other sources. The first of these was the PSD Data. This dataset derives from a largen convenience sample of participants who completed the Big Five Inventory. It has been used to demonstrate spatial clustering of personality traits, and the association of personality with political, economic, social, and health-based outcomes at the regional level (Peter J. Rentfrow, Jokela, and Lamb, 2015).

Despite the sample being self-selected and online-only, it achieves high correlations at the local authority district level with census counts of population, age, and ethnicity $(\mathrm{r}=.79$ to $\mathrm{r}=.93$, Peter J. Rentfrow, Jokela, and Lamb, 2015). This, coupled with the extremely large sample size, gives confidence that the personality mean estimates are of high quality.

\subsubsection{Aggregation of Individual Data}

The final data source for constituency-level estimation is the main individuallevel dataset. We combine all waves of the BES and BSA that have data on respondents' constituency and at least one of Right-wing Authoritarianism (RWA), Social Dominance Orientation (SDO), Openness, or Conscientiousness. This amounts to 119,330 data points for RWA; 6,645 for SDO, 51,233 for Openness, and 51,235 for Conscientiousness.

Regrettably, upon grouping by constituency, the sample size for SDO (n $=6,645$ ) collapses to a mere 11.56 data points per constituency, with no constituency represented by more than 30 participants. Meanwhile, RWA samples have a mean of 137.41 data points per constituency with only one constituency, $\mathrm{Na}$ h-Eileanan an Iar (The Western Isles) represented by fewer than 50 participants (at 44). While a formal cut-off for mean estimation is a viable method (i.e. removing participants from constituencies with, say, $\mathrm{n}<50$ ), Hoover and Dehghani (2020) note that such a method represents a confound if data sparsity is non-random. In the case of The Western Isles, this is clearly the case - the area's low population density, low internet connectivity, and low Conscientiousness all represent plausible theories of non-response.

Therefore, for each variable we must either exclude all constituencies or none. From the sample sizes available, it is clear that it is impossible to generate reliable mean estimates for SDO, and thus its role is not tested any further, whereas for RWA, Openness, and Conscientiousness, the data is sufficient to proceed.

\subsubsection{Mean Estimation for Constituency Psychological Variables}

In order to decide whether or not to weight the BES/BSA aggregate data before calculating constituency means, both weighted and unweighted means are calculated and correlated with the PSD data and a well-known correlate of all 


\begin{tabular}{|c|c|c|c|}
\hline Openness & $\begin{array}{l}\text { Unweighted } \\
\text { Mean }\end{array}$ & Weighted Mean & PSD Mean \\
\hline $\begin{array}{l}\text { Unweighted } \\
\text { Mean }\end{array}$ & - & - & - \\
\hline Weighted Mean & $\begin{array}{c}r(629)=.89 \\
p<.001\end{array}$ & - & - \\
\hline PSD Mean & $\begin{array}{c}r(629)=.57 \\
p<.001\end{array}$ & $\begin{array}{c}r(629)=.48 \\
p<.001\end{array}$ & - \\
\hline Leave Votes & $\begin{array}{c}r(152)=-.62 \\
p<.001\end{array}$ & $\begin{array}{c}r(152)=-.49 \\
p<.001\end{array}$ & $\begin{array}{c}r(152)=-.76 \\
p<.001\end{array}$ \\
\hline Conscientiousness & $\begin{array}{l}\text { Unweighted } \\
\text { Mean }\end{array}$ & Weighted Mean & PSD Mean \\
\hline $\begin{array}{l}\text { Unweighted } \\
\text { Mean }\end{array}$ & - & - & - \\
\hline Weighted Mean & $\begin{array}{c}r(629)=.88 \\
p<.001\end{array}$ & - & - \\
\hline PSD Mean & $\begin{array}{c}r(629)=.48 \\
p<.001\end{array}$ & $\begin{array}{c}r(629)=.41 \\
p<.001\end{array}$ & - \\
\hline Leave Votes & $\begin{array}{c}r(152)=.29 \\
p<.001\end{array}$ & $\begin{array}{c}r(152)=.23 \\
\mathrm{p}=.004\end{array}$ & $\begin{array}{c}r(152)=.42 \\
p<.001\end{array}$ \\
\hline
\end{tabular}

Table 1: Correlation Matrix for Constituency-level Personality Metrics.

three measures - the Brexit referendum results ${ }^{6}$. Because the unweighted data correlates more strongly with third party data than does data weighted with available weights, we can assume that the application of weights is counterproductive in this instance. Therefore, in the case of RWA (Table 2), we proceed with unweighted estimates, and for personality (Table 1), the unweighted estimates are used in a sample-size weighted average with the PSD data to produce final constituency estimates.

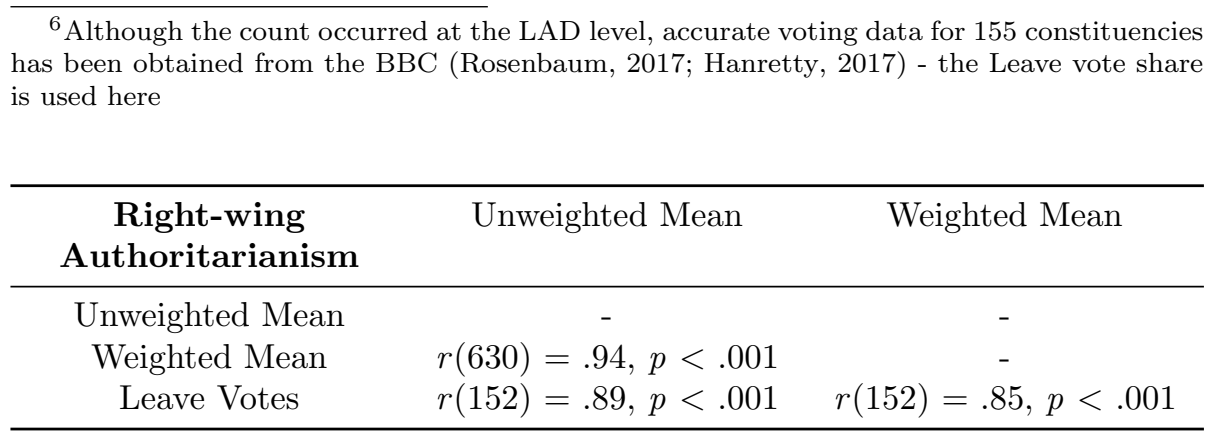

Table 2: Correlation Matrix for Constituency-level Authoritarianism Metrics. 


\subsection{Model Selection}

The appropriate model by which to test the relationships of multiple variables with a binary outcome is a binomial logistic regression. Specifically, it allows us to estimate the expected change in the log odds of the dependent variable when any given independent variable is incremented by 1 unit whilst controlling for all other independent variables in the model. This is important, because it allows us to dissociate the individual component of an effect from its constituency component. By including pairs of variables (i.e. constituency and individual ethnicity), the logistic regression calculates the pair of coefficients that maximise likelihood - isolating the constituency and individual components. If there is no neighbourhood effect, only individual effects, then the coefficient for constituency effects should be zero, because all of the predictive value of ethnicity will have been provided by the individual-level variable.

\subsection{Power, Significance, and Model Fit}

The alpha is set at $\mathrm{p}<0.05$. In order to correct for multiple testing, HolmBonferroni corrections are applied within each model for each independent variable included as a hypothesis test to preserve the Type I error rate. Control variables present in the model but not focal to the hypotheses are not included in the correction.

Beyond formal hypothesis testing, two performance indicators assess the quality of the models' fit to the data. To assess underfitting, Nagelkerke's pseudo- $R^{2}$ is reported as a measure of the models' in-sample goodness-of-fit. Unlike linear $R^{2}$, Nagelkerke's value cannot be interpreted as a measure of variance explained, only as a relative measure of fit.

Overfitting is a particular risk for our parameter-dense models. To address this, we also use a k-folds cross validation, reporting the mean out-of-sample prediction error for $\mathrm{k}=10$. To contextualise this value, it is compared to the full-model prediction error.

\subsection{Smallest Effect Size of Interest (SESOI)}

Anvari and Lakens (2019) suggest that researchers should consider the smallest effect size that could be considered "theoretically or practically significant", which they refer to as the SESOI. They argue that this is domain-specific, and that conventions like Cohen's recommendations on effect size interpretation should be used only when no better context is available. Especially given a large sample size, the SESOI protects against overclaiming by benchmarking results against grounded criteria.

We cannot use logistic regression coefficients for this purpose, because they are highly sensitive to the range of the variable they represent. The purpose of the SESOI is to ground the effect size in real-world consequences, so we work backwards from a substantial outcome to an effect size. In principle, the smallest outcome of interest in a general election would be a single vote. 
But aside from being undetectable, such an event also has little bearing on actual policy outcomes. The swing of a single constituency is of interest, but under first-past-the-post, the most marginal seats can sometimes be won by just a handful of votes. Therefore the swing of the single most marginal seat is discounted as a measure due to its volatility.

Instead, we derive our smallest effect size of interest from the mean margin of victory in an 'average marginal seat'. We define these seats as those that comprise the governing majority. In the elections that we study (1992-2019), the average largest party won 33 more seats than they needed for a majority. Because the SESOI should not be tied to the eventual outcome of each election (this would create different standards for each election analysed), we look at the 33 most marginal seats in each election, regardless of whether these in fact comprised the governing majority. We reason that the ability to swing an average marginal seat would certainly be an effect size of interest to a political party.

Across the 9 general elections that we study, the average MP in one of the 33 least secure seats has a constituency majority of $0.73 \%$. We therefore consider any effect that could change the distribution of votes (the dependent variable) by at least $0.73 \%$ to be of interest. We calculate this by applying the model to hypothetical versions of the dataset in which every respondent scored at the minimum and maximum of the variable of interest, while holding their other data static. Where the difference in predicted vote distributions between these two hypothetical scenarios is greater than $0.73 \%$, the variable is considered to have surpassed the 'smallest effect size of interest'.

\section{Results}

The results presented here are from the 'preferred analysis' of the 2019 general election. This is simply to avoid cluttering the main body text with extensive regression tables. The 2019 election was chosen solely on the grounds of its recency. Equivalent results for other elections are presented in the Supplementary Material, and where relevant they are referenced in this section.

\subsection{Spatial Distribution Metrics}

As per Section 1.5, a prerequisite to a neighbourhood effect is substantial variance and non-random distribution of constituency features. We therefore present salient descriptive statistics for all neighbourhood-level variables, including Queens-adjacency Moran's I (see Table 3). Conservative vote share is also presented for comparison. Note that RWA, Openness, and Conscientiousness have been z-scored between subjects, so the individual-level mean $=0$, and upon aggregation, mean $\approx 0$. All measures show a substantial degree of spatial autocorrelation, suggesting geographic clustering. For the psychological variables, this is visualised in Figure 1. 


\begin{tabular}{cccc}
\hline Variable & Mean & $\begin{array}{c}\text { Standard } \\
\text { Deviation }\end{array}$ & Moran's I \\
\hline Age & 39.70 & 3.10 & .53 \\
Class & 1.49 & 0.25 & .47 \\
Education & 2.05 & 0.33 & .54 \\
Unemployment & 4.37 & 1.42 & .52 \\
$\quad$ (\%) & & & \\
Removed from & 33.84 & 4.67 & .38 \\
Labour Force & & & \\
$\quad$ \%) & & 14.94 & .70 \\
Ethnicity & 87.94 & & .50 \\
(White \%) & & 0.27 & .45 \\
$\quad$ RWA & 0.02 & 0.91 & .69 \\
Openness & 0.01 & 0.90 & \\
Conscientiousness & 0.01 & 16.81 & \\
\hline Conservative & 43.94 & & \\
vote share (\%) & & & \\
\hline
\end{tabular}

Table 3: Spatial and Descriptive statistics for neighbourhood-level variables.
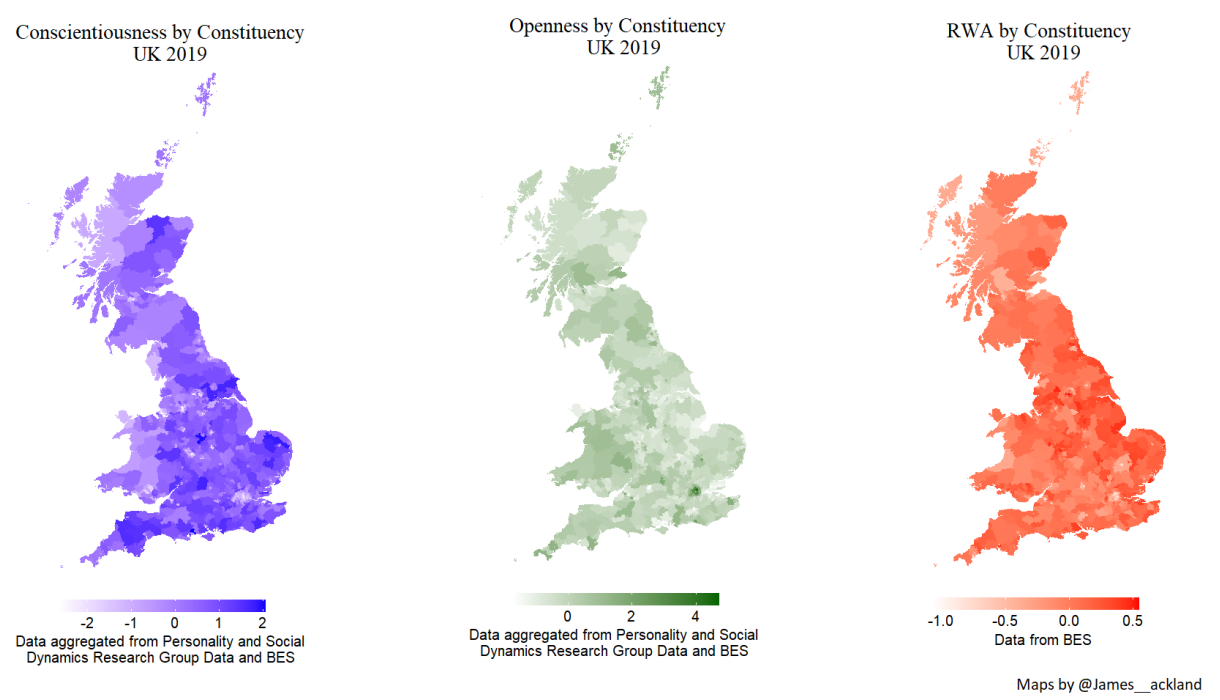

Figure 1: Constituency Personality Profiles (Data valid as of 2019) 


\subsection{Demographic Neighbourhood Effects}

The first model, comprising only demographic neighbourhood effects, shows concerning multicollinearity on two variables (Constituency: Mean Social Class, GVIF $=11.72$; Constituency: Mean Education, GVIF $=10.19)$, confirmed by the extremely high constituency-level correlation between education and social class $r(648)=.91, p<.001$. The decision to drop a variable in case of high multicollinearity was preregistered, conditional on the preservation of the ability to test hypotheses. While neighbourhood effects of social class and education were hypothesised as independent effects, their high correlation makes such a hypothesis untenable, and we thus continue with only social class. The decision to retain social class over education is due to its greater univariate association with the Labour against Conservative dependent variable (Constituency Class: $t(17424)=8.56, p<.001, \mathrm{~d}=.12$; Constituency Education: $t(16025)=-3.8, p$ $<.001, \mathrm{~d}=-.06)$. For ease of comparison, and because nesting is necessary to test hypothesis H3, mean education is also dropped from all subsequent models relating to 2019, regardless of VIF. This model also tested two control variables (aside from the individual-level analogues of the neighbourhood variables) nation, and political attention. Of these, nation was a significant predictor of the dependent variable, and was retained, whereas political attention was not.

The reparameterised model returns a statistically significant neighbourhood effect for age, ethnicity and unemployment, but not class. These effects all exceed the SESOI, and we can also estimate their size in terms of an odds ratio. Holding all other variables even, a decrease of 1 year in the average age of a voter's constituency is associated with a $10 \%$ increase in the odds of that person voting for the Labour party over the Conservatives, regardless of their own age. Similarly, a 1\%-point increase in the constituency unemployment rate is associated with a $33 \%$ increase in those odds, and a 1\%-point increase in the white population is, perhaps contrary to expectations, associated with a $2 \%$ increase. This is verified by models in which the dependent variable is Labour against not-Labour, and Conservative against not-Conservative (see Table 4). Across all three dependent variables, those living in younger, whiter, and higher unemployment constituencies are more likely to vote Labour and less likely to vote Conservative, even when controlling for the individuals' own age, ethnicity, and working status.

These neighbourhood effects are pervasive in models of other years (see Fig. 2 ), although there are exceptions, particularly in older elections where data quantity and quality decrease. Effects for constituency-level unemployment are the least robust. We are unable to detect these in $4(1992,1997,2001,2016)$ polls out of 9 studied, when comparing votes for the Conservative party (or Leave campaign) to other voting behaviours. Ethnicity and age-based neighbourhood effects are also not always detected in 1997 or in the Brexit referendum (see Supplementary Material for full regression tables of other years). Nonetheless, in the vast majority of cases, a neighbourhood effect can be shown for these three variables, and wherever it is detected, it also exceeds the SESOI. The evidence for an education-based neighbourhood effect in the Brexit referendum 
is particularly strong - for a one unit increase in neighbourhood education, residents have a $76 \%$ increase in their odds of voting to Remain rather than Leave.

Table 4: Model 1: Demographic Neighbourhood Effects (2019)

\begin{tabular}{lccc}
\hline \hline & \multicolumn{3}{c}{ Dependent variable: } \\
\cline { 2 - 3 } & Lab against Con & Lab against not-Lab & Con against not-Con \\
& $(1)$ & $(2)$ & $(3)$ \\
\hline Lives in Scotland & $-0.211(0.043)$ & $-1.320(0.000)$ & $-0.775(0.000)$ \\
Lives in Wales & $0.418(0.000)$ & $0.169(0.031)$ & $-0.304(0.000)$ \\
Individual: Male & $-0.109(0.041)$ & $-0.176(0.000)$ & $0.042(0.269)$ \\
Individual: Age & $-0.029(0.000)$ & $-0.012(0.000)$ & $0.025(0.000)$ \\
Individual: Education & $0.148(0.000)$ & $0.092(0.000)$ & $-0.099(0.000)$ \\
Individual: Social Class & $-0.077(0.000)$ & $-0.017(0.268)$ & $0.074(0.000)$ \\
Individual: Removed from Labour Force & $0.087(0.199)$ & $0.007(0.887)$ & $-0.082(0.092)$ \\
Individual: Unemployed & $0.262(0.324)$ & $0.153(0.393)$ & $-0.266(0.201)$ \\
Individual: White & $-0.586(0.000)$ & $-0.444(0.000)$ & $0.358(0.004)$ \\
Individual: Openness & $0.088(0.000)$ & $0.049(0.000)$ & $-0.057(0.000)$ \\
Individual: Conscientiousness & $-0.096(0.000)$ & $-0.045(0.000)$ & $0.076(0.000)$ \\
Individual: RWA & $-0.906(0.000)$ & $-0.510(0.000)$ & $0.705(0.000)$ \\
Constituency: Mean Age & $-0.092(0.000)$ & $-0.087(0.000)$ & $0.032(0.004)$ \\
Constituency: Mean Social Class & $0.318(0.111)$ & $-0.369(0.035)$ & $-0.444(0.003)$ \\
Constituency: Unemployment (\%) & $0.289(0.000)$ & $0.149(0.000)$ & $-0.178(0.000)$ \\
Constituency: Removal from Labour Force (\%) & $0.030(0.000)$ & $0.008(0.103)$ & $-0.029(0.000)$ \\
Constituency: White (\%) & $0.023(0.000)$ & $0.020(0.000)$ & $-0.009(0.002)$ \\
Constant & $3.691(0.000)$ & $2.615(0.001)$ & $-3.141(0.000)$ \\
\hline Observations & 10,461 & 15,240 & 15,240 \\
Log Likelihood & $-5,514.200$ & $-7,772.100$ & $-9,365.200$ \\
Akaike Inf. Crit. & $11,064.000$ & $15,580.000$ & $18,766.000$ \\
\hline \hline
\end{tabular}

Bracketed figured are p-values.

Despite these relatively large and significant effects, the models are not particularly well-fit ${ }^{7}$ : Labour against Conservative (Nagelkerke's $\mathrm{R}^{2}=.29$, fullmodel prediction error $=.26$ ); Labour against not-Labour (Nagelkerke's $\mathrm{R}^{2}=$ .13 , full-model prediction error $=.24)$; Conservative against not-Conservative (Nagelkerke's $\mathrm{R}^{2}=.20$, full-model prediction error $=.34$ ). There is no evidence of overfit, however, as the cross-validation error is almost identical to the full model error (K-folds mean prediction errors: Lab/Con $=.26$, Lab/not-Lab $=.24$, Con $/$ not-Con $=.35)^{8}$. The lower fits on Labour against not-Labour are likely explained by greater similarity between people who vote Labour and people who vote for third parties or abstain.

\subsection{Psychological Neighbourhood Effects}

The second model includes neighbourhood level psychological variables. We observe statistically significant neighbourhood effects above the SESOI for Conscientiousness and RWA, but not for Openness. However, the pattern of coefficients is more complex than for demographic neighbourhood effects. Those living in

\footnotetext{
${ }^{7}$ Recall that Nagelkerke's $\mathrm{R}^{2}$ cannot be compared to linear $\mathrm{R}^{2}$, so in this case the full-model prediction error is the better indicator of the weak-to-moderate fit.

${ }^{8}$ The full-sample and cross-validation errors do differ slightly, but detection of these differences requires accuracy to the third significant figure.
} 
areas higher on Conscientiousness and RWA are less likely to vote Labour than Conservative, but when the distinction is between Labour and not Labour, constituency RWA is not a significant predictor of voting, and when the distinction is between Conservative and not Conservative, constituency Conscientiousness is not significant. Yet the effect sizes are large: a 1 unit increase in constituency Conscientiousness corresponds to a $25 \%$ increase in the odds of voting Conservative over Labour, while a 1 unit increase in constituency RWA corresponds to a $91 \%$ increase.

All demographic neighbourhood effects observed in model 1 remain significant and above the SESOI through the addition of psychological effects, with the exception of constituency age, which no longer predicts Conservative vs. not-Conservative voting.

Table 5: Model 2: Psychological Neighbourhood Effects (2019)

\begin{tabular}{lccc}
\hline \hline & \multicolumn{3}{c}{ Dependent variable: } \\
\cline { 2 - 3 } & Lab against Con & Lab against not-Lab & Con against not-Con \\
& $(1)$ & $(2)$ & $(3)$ \\
\hline Lives in Scotland & $-0.402(0.000)$ & $-1.343(0.000)$ & $-0.579(0.000)$ \\
Lives in Wales & $0.335(0.001)$ & $0.135(0.090)$ & $-0.224(0.005)$ \\
Individual: Male & $-0.107(0.047)$ & $-0.177(0.000)$ & $0.037(0.340)$ \\
Individual: Age & $-0.029(0.000)$ & $-0.012(0.000)$ & $0.026(0.000)$ \\
Individual: Education & $0.144(0.000)$ & $0.093(0.000)$ & $-0.095(0.000)$ \\
Individual: Social Class & $-0.076(0.000)$ & $-0.017(0.256)$ & $0.073(0.000)$ \\
Individual: Removed from Labour Force & $0.095(0.159)$ & $0.009(0.871)$ & $-0.091(0.063)$ \\
Individual: Unemployed & $0.268(0.312)$ & $0.147(0.410)$ & $-0.266(0.201)$ \\
Individual: White & $-0.591(0.000)$ & $-0.448(0.000)$ & $0.360(0.004)$ \\
Individual: Openness & $0.085(0.000)$ & $0.049(0.000)$ & $-0.054(0.000)$ \\
Individual: Conscientiousness & $-0.095(0.000)$ & $-0.045(0.000)$ & $0.074(0.000)$ \\
Individual: RWA & $-0.901(0.000)$ & $-0.513(0.000)$ & $0.694(0.000)$ \\
Constituency: Mean Age & $-0.048(0.007)$ & $-0.069(0.000)$ & $0.002(0.881)$ \\
Constituency: Mean Social Class & $-0.220(0.369)$ & $-0.308(0.106)$ & $0.100(0.545)$ \\
Constituency: Unemployment (\%) & $0.243(0.000)$ & $0.128(0.000)$ & $-0.172(0.000)$ \\
Constituency: Removal from Labour Force $(\%)$ & $0.006(0.451)$ & $0.002(0.782)$ & $-0.010(0.093)$ \\
Constituency: White (\%) & $0.023(0.000)$ & $0.019(0.000)$ & $-0.010(0.000)$ \\
Constituency: Mean Openness & $-0.049(0.333)$ & $-0.070(0.158)$ & $-0.028(0.458)$ \\
Constituency: Mean Conscientiousness & $-0.221(0.000)$ & $-0.155(0.001)$ & $0.072(0.125)$ \\
Constituency: Mean RWA & $-0.648(0.006)$ & $-0.007(0.966)$ & $0.683(0.000)$ \\
Constant & $3.824(0.000)$ & $2.222(0.004)$ & $-3.372(0.000)$ \\
\hline Observations & 10,461 & 15,240 & 15,240 \\
Log Likelihood & $-5,489.900$ & $-7,762.400$ & $-9,335.200$ \\
Akaike Inf. Crit. & $11,022.000$ & $15,567.000$ & $18,712.000$ \\
\hline \hline
\end{tabular}

Bracketed figured are p-values.

Once again, model fits are lower than expected, and there is minimal evidence of overfitting. Labour against Conservative (Nagelkerke's $\mathrm{R}^{2}=.29$, fullmodel prediction error $=.26, \mathrm{~K}$-folds mean prediction error $=.26$ ); Labour against not-Labour (Nagelkerke's $\mathrm{R}^{2}=.13$, full-model prediction error $=.24$, $\mathrm{K}$-folds mean prediction error $=.24)$; Conservative against not-Conservative (Nagelkerke's $\mathrm{R}^{2}=.21$, full-model prediction error $=.34, \mathrm{~K}$-folds mean prediction error $=.34$ ). Largely, these represent very minor improvements upon the model fits in Model 1, but since Model 1 is nested in Model 2, this is a statistical necessity. The scale of these improvements is explored more fully under Section 
4.4 .

\subsection{The Independence of Psychological and Demographic Neighbourhood Effects}

Across all three dependent variables we observe a significant reduction of deviance between a neighbourhood effect model with psychological characteristics against one with only demographics (See Table 6).

\begin{tabular}{ccc}
\hline Dependent Variable & Likelihood Ratio Test & $\begin{array}{c}\text { Deviance Reduction } \\
(\%)\end{array}$ \\
\hline Labour against & $\operatorname{LRT}(3)=48.65$, & 0.43 \\
Conservative & $p<.001$ & 0.11 \\
Labour against & $\operatorname{LRT}(3)=19.37$, & \\
not-Labour & $p=.002$ & 0.30 \\
Conservative against & $\operatorname{LRT}(3)=59.89$, & \\
not-Conservative & $p<.001$ & \\
\hline
\end{tabular}

Table 6: Likelihood Ratio Test for Model 2 against Model 1

However, the effect sizes here are negligible. With no more than a $0.5 \%$ reduction in deviance, it is clear that the addition of psychological neighbourhood effects has no substantial impact on model fit when individual effects and demographic neighbourhood effects are already fitted. This is in spite of the fact that the effects are individually significant and relatively large within the models (see Table 5). A viable explanation for this is that the substantial deviance explained by psychological neighbourhood effects in model 2 was already explained by demographic neighbourhood effects or some control variable in model 1 . This would be detected in the models as a large decrease in the absolute value of a coefficient between models 2 and 1 . Upon inspection of the coefficients, all demographic neighbourhood effects, with the exception of ethnicity, are substantially reduced in magnitude when psychological neighbourhood effects are introduced to the model.

\subsection{Moderation of the Neighbourhood Effect}

Finally, we test whether each neighbourhood effect is moderated by extraversion, social norms, neighbourhood social capital or social trust. We find no evidence to support that any of these variables is individually moderating any neighbourhood effect. These interaction models have substantially reduced sample size, and a large number of comparisons for the Holm-Bonferroni correction to adjust for. These joint pressures on p-values may explain the failure to find any effect (See Table 7). 
Table 7: Model 4: Moderators of Neighbourhood Effects (2019)

\begin{tabular}{|c|c|c|c|}
\hline & \multicolumn{3}{|c|}{ Dependent variable: } \\
\hline & $\begin{array}{c}\text { Lab against Con } \\
\text { (1) }\end{array}$ & $\begin{array}{c}\text { Lab against not-Lab } \\
(2)\end{array}$ & $\begin{array}{c}\text { Con against not-Con } \\
\text { (3) }\end{array}$ \\
\hline Individual: Male & $-0.130(0.213)$ & $-0.185(0.029)$ & $0.038(0.615)$ \\
\hline Individual: Age & $-0.037(0.000)$ & $-0.020(0.000)$ & $0.028(0.000)$ \\
\hline Individual: Education & $0.148(0.001)$ & $0.090(0.015)$ & $-0.101(0.001)$ \\
\hline Individual: Social Class & $-0.141(0.000)$ & $-0.090(0.002)$ & $0.068(0.009)$ \\
\hline Individual: Removed from Labour Force & $0.095(0.453)$ & $-0.048(0.637)$ & $-0.197(0.032)$ \\
\hline Individual: Unemployed & $0.464(0.321)$ & $-0.071(0.824)$ & $-0.366(0.321)$ \\
\hline Individual: White & $-0.584(0.052)$ & $-0.260(0.207)$ & $0.316(0.189)$ \\
\hline Individual: Openness & $0.076(0.017)$ & $0.032(0.221)$ & $-0.081(0.001)$ \\
\hline Individual: Conscientiousness & $-0.101(0.000)$ & $-0.046(0.044)$ & $0.083(0.000)$ \\
\hline Individual: RWA & $-0.817(0.000)$ & $-0.476(0.000)$ & $0.633(0.000)$ \\
\hline Individual: Extraversion & $0.951(0.087)$ & $0.652(0.134)$ & $-0.027(0.945)$ \\
\hline Individual: Social Trust & $0.134(0.913)$ & $-0.091(0.925)$ & $-0.484(0.570)$ \\
\hline Individual: Voting Norms & $0.970(0.493)$ & $1.114(0.315)$ & $-0.838(0.359)$ \\
\hline Individual: Neighbourhood Social Capital & $-0.956(0.441)$ & $-0.388(0.688)$ & $-0.838(0.324)$ \\
\hline Constituency: Mean Age & $0.007(0.922)$ & $-0.058(0.301)$ & $0.027(0.591)$ \\
\hline Constituency: Mean Education & $0.132(0.737)$ & $0.621(0.040)$ & $0.041(0.881)$ \\
\hline Constituency: Unemployment (\%) & $0.234(0.114)$ & $0.069(0.520)$ & $-0.130(0.229)$ \\
\hline Constituency: Removal from Labour Force (\%) & $0.061(0.038)$ & $0.052(0.020)$ & $-0.043(0.056)$ \\
\hline Constituency: White (\%) & $0.028(0.047)$ & $0.023(0.027)$ & $-0.025(0.011)$ \\
\hline Constituency: Mean Openness & $-0.013(0.901)$ & $-0.029(0.727)$ & $-0.031(0.683)$ \\
\hline Constituency: Mean Conscientiousness & $-0.264(0.229)$ & $-0.277(0.110)$ & $-0.012(0.937)$ \\
\hline Constituency: Mean RWA & $-0.674(0.303)$ & $1.018(0.045)$ & $0.887(0.071)$ \\
\hline Individual: Extraversion*Constituency: Mean Age & $-0.010(1.000)$ & $-0.005(1.000)$ & $-0.011(1.000)$ \\
\hline Individual: Social Trust ${ }^{*}$ Constituency: Mean Age & $-0.002(1.000)$ & $-0.013(1.000)$ & $0.010(1.000)$ \\
\hline Individual: Voting Norms*Constituency: Mean Age & $-0.037(1.000)$ & $-0.026(1.000)$ & $0.030(1.000)$ \\
\hline Individual: Neighbourhood Social Capital*Constituency: Mean Age & $0.030(1.000)$ & $0.043(1.000)$ & $0.034(1.000)$ \\
\hline Individual: Extraversion*Constituency: Unemployment (\%) & $-0.012(1.000)$ & $0.010(1.000)$ & $-0.011(1.000)$ \\
\hline Individual: Social Trust*Constituency: Unemployment (\%) & $-0.045(1.000)$ & $0.012(1.000)$ & $0.071(1.000)$ \\
\hline Individual: Voting Norms*Constituency: Unemployment (\%) & $0.075(1.000)$ & $0.004(1.000)$ & $-0.014(1.000)$ \\
\hline Individual: Neighbourhood Social Capital*Constituency: Unemployment (\%) & $0.104(1.000)$ & $0.041(1.000)$ & $-0.045(1.000)$ \\
\hline Individual: Extraversion*Constituency: Unemployment (\%) & $-0.011(1.000)$ & $-0.010(1.000)$ & $0.008(1.000)$ \\
\hline Individual: Social Trust*Constituency: Removal from Labour Force (\%) & $0.004(1.000)$ & $0.008(1.000)$ & $0.002(1.000)$ \\
\hline Individual: Voting Norms*Constituency: Removal from Labour Force (\%) & $0.004(1.000)$ & $0.002(1.000)$ & $-0.001(1.000)$ \\
\hline Individual: Neighbourhood Social Capital ${ }^{*}$ Constituency: Removal from Labour Force (\%) & $-0.016(1.000)$ & $-0.012(1.000)$ & $0.005(1.000)$ \\
\hline Individual: Extraversion*Constituency: White $(\%)$ & $-0.002(1.000)$ & $-0.002(1.000)$ & $0.003(1.000)$ \\
\hline Individual: Social Trust*Constituency: White (\%) & $0.001(1.000)$ & $0.003(1.000)$ & $-0.004(1.000)$ \\
\hline Individual: Voting Norms*Constituency: White (\%) & $0.003(1.000)$ & $0.002(1.000)$ & $-0.001(1.000)$ \\
\hline Individual: Neighbourhood Social Capital ${ }^{*}$ Constituency: White (\%) & $-0.001(1.000)$ & $-0.013(0.270)$ & $-0.006(1.000)$ \\
\hline Individual: Extraversion*Constituency: Mean RWA & $0.170(1.000)$ & $0.057(1.000)$ & $-0.067(1.000)$ \\
\hline Individual: Social Trust: ${ }^{\text {Constituency: Mean RWA }}$ & $0.267(1.000)$ & $0.379(1.000)$ & $0.054(1.000)$ \\
\hline Individual: Voting Norms*Constituency: Mean RWA & $-0.456(1.000)$ & $-0.171(1.000)$ & $0.146(1.000)$ \\
\hline Individual: Neighbourhood Social Capital*Constituency: Mean RWA & $-0.016(1.000)$ & $0.218(1.000)$ & $0.116(1.000)$ \\
\hline Individual: Extraversion*Constituency: Mean Conscientiousness & $-0.001(1.000)$ & $0.030(1.000)$ & $0.053(1.000)$ \\
\hline Individual: Social Trust*Constituency: Mean Conscientiousness & $0.0005(1.000)$ & $0.001(1.000)$ & $0.007(1.000)$ \\
\hline Individual: Voting Norms*Constituency: Mean Conscientiousness & $0.198(1.000)$ & $0.082(1.000)$ & $-0.051(1.000)$ \\
\hline Individual: Neighbourhood Social Capital*Constituency: Mean Conscientiousness & $-0.060(1.000)$ & $-0.111(1.000)$ & $-0.059(1.000)$ \\
\hline Constant & $-0.778(0.797)$ & $-1.320(0.576)$ & $-1.696(0.429)$ \\
\hline Observations & 2,920 & 4,061 & 4,061 \\
\hline Log Likelihood & $-1,519.300$ & $-2,056.200$ & $-2,510.800$ \\
\hline Akaike Inf. Crit. & $3,132.500$ & $4,206.300$ & $5,115.600$ \\
\hline
\end{tabular}

Bracketed figured are p-values. 


\subsection{Time-series Trends}

As demonstrated by Johnston, Propper, Burgess, et al. (2005), neighbourhood effects can strengthen and weaken over time. This may be in response to party strategy, as they suggest, but it may also occur if the salience of certain characteristics of a neighbourhood change, or if the mapping of characteristics to partisanship changes. The joint phenomena of class dealignment and the increasing importance of 'values' after Brexit (Bale et al., 2020), are individual-level trends that might be mirrored in neighbourhood effects. The trends discussed are not subject to formal hypothesis testing, because no such hypotheses were preregistered, but they are presented as necessary context for the effects mentioned in the preceding sections.

To standardise effects within and between models, two amendments to the previous modelling strategy are made. First, the outcome of interest is the Wald score, rather than the coefficient. This is used to standardise between measures that have different practical ranges (such as mean RWA score and percentage unemployment). ${ }^{9}$ Second, the logit models used to generate these coefficients retain all available individual-level control variables, but test only one neighbourhood variable at a time. Notably, in Figure 2, neighbourhood effects all follow the same pattern with regard to their absolute magnitude, showing weak predictive value around the turn of the millenium, peaking in importance in the coalition years of 2010 and 2015, before waning again after the Brexit referendum. The trend of whether or not neighbourhood in general matters in a given election is more visible than which neighbourhood effects matter. To better visualise the comparative importance of each neighbourhood effect, we control for 'election effects' by dividing each effect's Wald score by the average absolute Wald score for that election. The resulting trends reveal that the relative importance of each effect is very consistent over time, as is their rank-order, with employment, class and Conscientiousness consistently being the most useful neighbourhood effects considered (see Figure 3). For context, this can be compared to an equivalent plot of the predictive value of individual-level effects between elections, which shows great variation, including class dealignment and the increasing importance of RWA over the same period (see figure 4).

\section{Summary of Main Findings}

The findings presented in this research demonstrate the persistence of electoral neighbourhood effects in $21^{\text {st }}$ century British politics, including effects based on aggregate neighbourhood psychology.

We show evidence consistent with individuals being affected by the average age, ethnicity, and unemployment of their constituency when voting or migrat-

\footnotetext{
${ }^{9}$ When interpreting Wald scores, the absolute magnitude corresponds to the importance of the variable in predicting the dependent variable, whereas the sign corresponds to the direction of the association.
} 


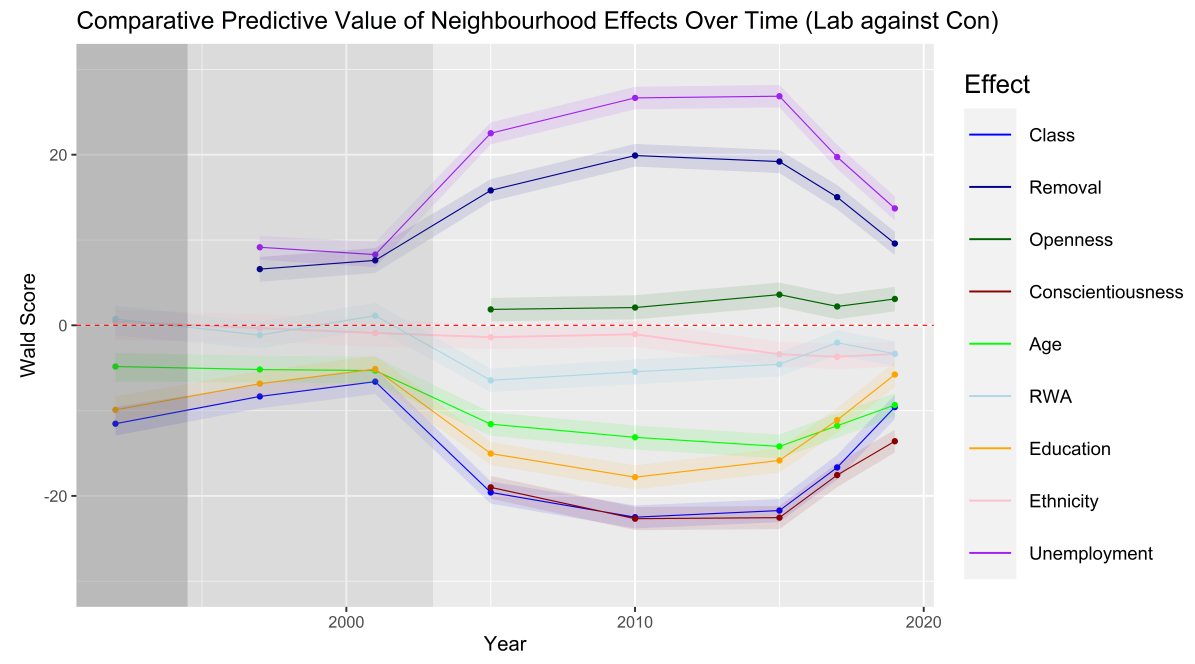

Figure 2: Wald score for each of the modelled neighbourhood effects across 8 general elections. Shaded ribbons are $95 \%$ bootstrapped confidence intervals. Prior to 2005, individual-level psychological data is not available, so the set of covariates changes, and thus estimates in this range cannot be directly compared to estimates in 2005 and beyond. Likewise, individual employment data is missing prior to 2001. The inclusion of individual-level psychological variables as covariates in 2010 suppresses the observed effect sizes relative to models in which these variables are omitted (not pictured). Therefore the 'true' rise in effect size between 2001 and 2005 is actually larger than implied here. These eras of available covariates are distinguished by grey shading. 


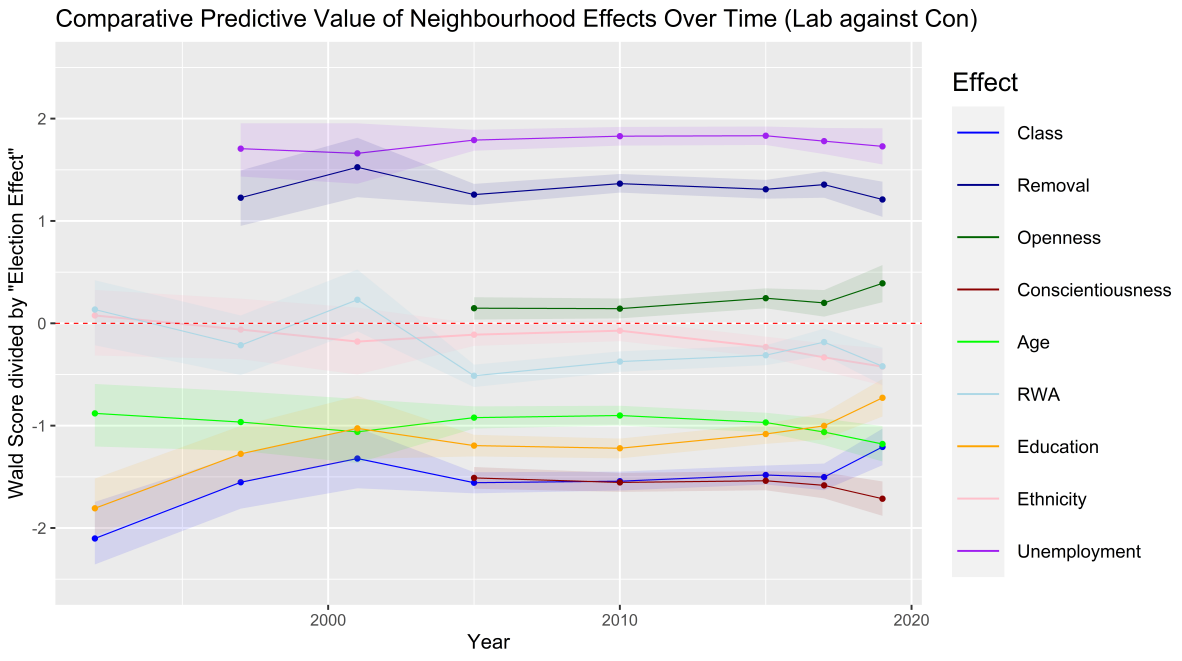

Figure 3: Wald score for each of the modelled neighbourhood effects across 8 general elections, divided by the mean neighbourhood effect within-elections. Shaded ribbons are 95\% bootstrapped confidence intervals. Prior to 2005, individual-level data for psychological variables is not available, so estimates in this range cannot be directly compared to estimates post-2005. Likewise, individual employment data is missing prior to 2001. 


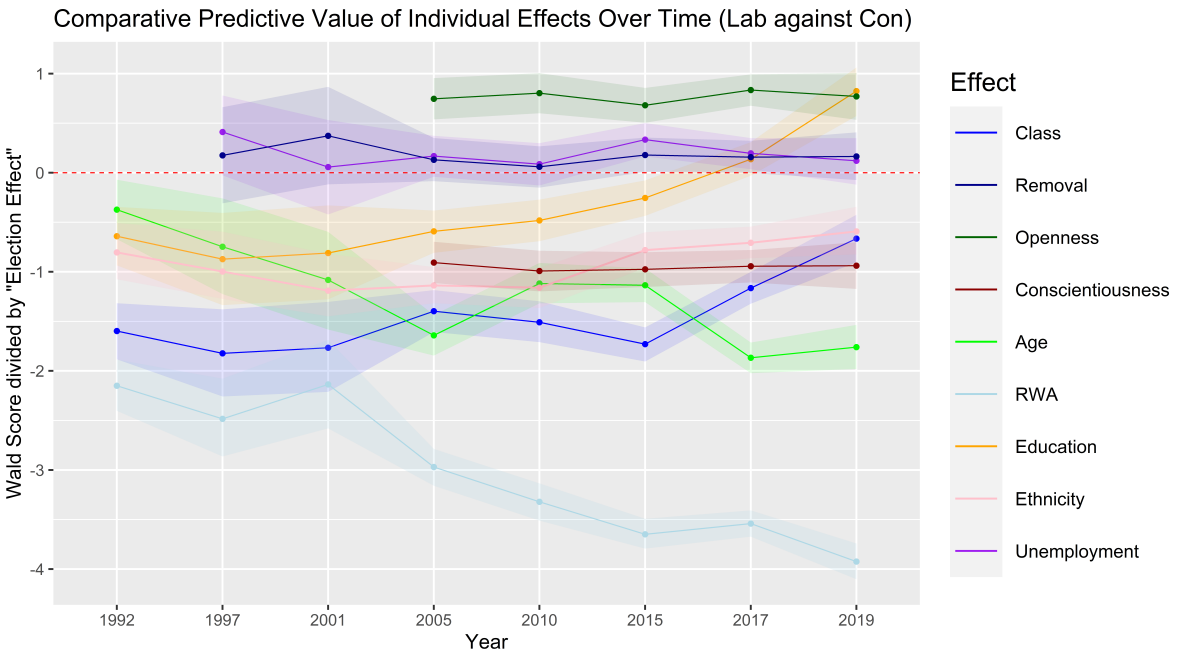

Figure 4: Wald score for each of the modelled individual effects across 8 general elections, divided by the mean effect within-elections. Shaded ribbons are $95 \%$ bootstrapped confidence intervals. Prior to 2005, individual-level data for psychological variables is not available, so estimates in this range cannot be directly compared to estimates post-2005. Likewise, individual employment data is missing prior to 2001 . 
ing, regardless of their own age, ethnicity, and employment status. Of these effects, age and unemployment work "consensually" (Miller, 1978) - that is, the neighbourhood effect works in the same direction as the individual effect. A person of any age in an elderly constituency is more likely to vote Conservative, and a person of any employment status in a high-unemployment constituency is more likely to vote Labour. Ethnicity, however, works "reactively" - a person in a less white constituency is more likely to vote Conservative, even though non-white individuals are themselves less likely to vote Conservative. Such reactive effects are somewhat harder to reconcile with an ideological migration mechanism.

We also advanced evidence that the psychological characteristics of constituencies - namely neighbourhood Conscientiousness and RWA - are associated with individual-level voting or migrating behaviour. Constituency RWA creates a particularly strong neighbourhood effect, implying that individuals are affected by the ideological orientation of their geographically-proximal peers.

While we demonstrated a statistically significant difference between the predictive power of voting models that include and exclude psychological neighbourhood effects, the size of this difference is small. When combined with the discovery of a relatively large neighbourhood effects, this appears a curious finding. Modest goodness-of-fit metrics eliminate a ceiling effect as an explanation for this. Rather, it appears that correlations between psychological and demographic variables at the regional level are sufficiently large that the variance in voting behaviour explainable by psychological neighbourhood effects can simply be subsumed by demographic effects (see Supplementary Material). This casts doubt on the utility of considering neighbourhood psychology if one's goal is purely the forecasting of individual votes, especially given the comparative ease of access to demographic spatial data over equivalent psychological data. However, there is value in academic theory beyond short-term electoral forecasting, and any such association between regional demographics and psychology may not prove to be durable.

Finally, we attempted to test the moderation of the neighbourhood effects that we observed. However, none of our hypothesised moderating variables, including our adaptation of Neighbourhood Social Capital, which has previously been successfully used as a moderator (Johnston, Propper, Sarker, et al., 2005), showed significant effects. The inability to find consistent evidence on the mechanism of neighbourhood effects continues to be a shortcoming of the theory. The number of covariates in the model preregistered to test this hypothesis may have constituted a barrier to discovery in this regard, especially given the use of a conservative Holm-Bonferroni correction. While further research may yet be fruitful in furthering our understanding of which types of people are most likely to be susceptible to neighbourhood effects, the present research was unable to return any such findings. 


\section{Discussion}

\subsection{Sample Validity and Representativeness}

Because our sample was drawn from multiple origins, features of its validity and representativeness are complex. Unlike many studies in adjacent fields, the sample is not solely online, because the BSA and early waves of the BES use postcode address files, which allow something closer to a truly random sample of the population, because more people have a postcode than access to online surveys. However, the mere existence of multiple sampling strategies is far from sufficient to demonstrate that the sample is valid and representative, and to the extent to which the sample is drawn from online surveys - which is particularly the case in later years of the study - the usual issues exist.

The overreliance on online-only methodology is a known pitfall, because access to the internet and time to complete surveys correlates with a host of known and unknown variables, including but certainly not limited to the "WEIRD" characteristics (Henrich, Heine, and Norenzayan, 2010). For the present research, it seems likely that people who are 'more online' are also likely to be less entrenched in their neighbourhood - to have low 'Neighbourhood Social Capital', which previous studies have shown to be associated with susceptibility to neighbourhood effects (Johnston, Propper, Sarker, et al., 2005). It may therefore be the case that our online sample is saturated with disconfirmatory cases, thus suppressing the true size of neighbourhood effects in proportion to the fraction of our sample that is online. Indeed the increasing role of the internet in our political and social lives would present a very reasonable hypothesis for a decrease in overall neighbourhood effects across the period studied, but in fact no such trend is observed (see Figure 2).

As with all survey research, a perfectly random sample is both desirable and unachievable, but in its absence, further research using new samples drawn from yet more diverse and valid sampling strategies would be welcome.

\subsection{Scope of Dependent Variable}

An important question our results can only partially answer is whether there are neighbourhood effects on turnout. Turnout, like party support, is known to show spatial distribution and clustering (Coleman, 2018; Salim Saib, 2017), and to have similar individual-level correlates to partisan voting behaviour including age and ethnicity (Heath and Khan, 2012), so in principle this research could extend to turnout. However, while abstainers are included in the 'not-Labour' and 'not-Conservative' categories, this does not allow their isolation. Work to establish whether, and which, neighbourhood effects predict voter turnout would be of great utility, not least because it might lead to recommendations for the alleviation of low turnout, which is among the less divisive goals in electoral politics.

The use of logistic regression modelling effectively confines researchers to 
binary conceptions of their dependent variables ${ }^{10}$. Yet, an important and longstanding debate in British political science focuses on the existence or otherwise of multi-partism in general elections (Dunleavy, 2005). Our selection of model and dependent variables implicitly assumes a binary political system. Across the range of election years analysed, only two parties, Labour and the Conservatives, have represented a meaningful electoral presence throughout the entire period. However, various third parties, particularly those whose strength is highly spatially clustered, have been competitive at specific points in that period.

Controlling for an individual's nation of residence presents a somewhat blunt statistical solution to account for the popularity of Plaid Cymru and the SNP. However, this solution is not a viable response to third parties whose support is cross-national, but localised to a handful of left-leaning population centres (like the Green party), or idiosyncratic constituencies (like the Liberal Democrats). A more sophisticated model, and an enormous sample size (sufficient to fairly represent the voting bases of these minor parties in every constituency) would be necessary to truly reflect the UK's multi-party system.

\subsection{Independent Variable Construction and Consistency}

Pragmatic decisions had to be made at times concerning the availability of independent and control variables. These will, in places, have reduced the validity of some measures, which - assuming effects are 'real' - will reduce the magnitude of observed associations.

Employment is one such example. Aside from being unavailable for any data in the 1992 election, the variable is also complex to construct when it is available (see Supplementary Material). Notably, the variable construction puts retirees and students in the same bracket. This is because they are both 'removed from the workforce' - they are not employed per se, but they also cannot be considered unemployed, because they have made an active decision not to seek work, and thus have none of the political views that might be associated with frustration at a lack of employment opportunities. However, students and retirees have typically very different political views, due in part to covariance with age. Because the working status variable is intended to capture variance in voting behaviour related to experiences with employment and not covariant experiences, this categorisation is valid, but its consequence is the creation of a highly heterogeneous category with somewhat complicated interpretation.

Data availability also affected variable reliability, with only non-standard measures available for RWA (Evans, Heath, and Lalljee, 1996), and only the shortest recognised measure for personality (Gosling, Peter J. Rentfrow, and Swann, 2003, TIPI, ). While more psychometrically sound options are available in the literature, their distribution to a sample size sufficient for research of this nature would be extremely costly.

\footnotetext{
${ }^{10}$ As discussed in Section 3.1, multinomial logit models do exist, but are essentially no different to binary models in interpretation.
} 


\subsection{Przeworski Effects and Non-linearity}

Recalling Miller (1978), there are three ways in which a neighbourhood effect might operate. Consensual effects are those in which neighbourhood variables predict voting in the same direction as at the individual level - these comprise the bulk of our findings. Reactive effects, which we find for ethnicity, predict voting in the opposite direction to the individual level. The Przeworski effect (Przeworski and Soares, 1971), refers to a case in which a neighbourhood effect drives polarisation. This is demonstrated by Miller (1977) in the specific case of a class-based effect on attitudes towards trade unions. He finds that middle-class people were always less supportive of trade unions than working-class people, but the size of this gap was larger in working-class areas.

Our model does not attempt to predict such non-linearity - a constituency effect must either move everyone towards the Conservatives or everyone towards Labour, or - in the eyes of our model - it doesn't exist. In order to test for Przeworski effects, interaction terms of individual-level variables against their corresponding constituency effect would have to be fitted. Such modelling was not undertaken because previous research has not uncovered Przeworski effects in British electoral patterns, but this is nonetheless a known blindspot of our statistical strategy.

A similar limitation comes from the decision not to fit quadratic (or other non-linear) independent variables. For instance, it may be the case that people in constituencies that are either very high or very low on measures of mean social grade vote Conservative, with the middle portion voting Labour. This is certainly consistent with the 'Red Wall' mythology. However, our models only test linear effects, due to a desire not to overly complicate our already lengthy models. Future research may wish to test for non-linearities (of which quadratic effects are only one type, albeit the most likely) in neighbourhood effects.

\section{Concluding Remarks}

This research has advanced substantial new evidence consistent with the theory that British voters are influenced by those in their neighbourhoods. While we were unable to establish how this influence operates, it is clear that as well as the social class of one's surroundings, the age, ethnicity, employment status, personality, and ideological orientation of one's geographic peers are associated with one's voting behaviour.

We provide clear evidence that neighbourhood characteristics predict voting patterns beyond individual characteristics. Political science and political psychology still have to bridge individual and contextual levels of analysis to understand the mechanisms creating these effects, but we can now better account for them in practical campaigning and polling settings. Voters do not exist in a vacuum, and we should not treat them as if they do. 


\section{References}

Aidt, Toke and Christopher Rauh (2018). "The Big Five Personality Traits and Partisanship in England". In: Electoral Studies 54, pp. 1-21. ISSN: 0261-3794. DOI: https://doi.org/10.1016/j.electstud.2018.04.017. URL: https: //www.sciencedirect.com/science/article/pii/S0261379418300234.

Anvari, Farid and Daniël Lakens (2019). "Using Anchor-Based Methods to Determine the Smallest Effect Size of Interest". In: Journal of Experimental Social Psychology 96.9. DOI: 10 .31234/osf . io/syp5a. URL: https: // psyarxiv.com/syp5a/.

Bale, Time et al. (June 2020). Mind the values gap. Report. The UK in a Changing Europe.

Borkenau, Peter and Anette Liebler (1993). "Convergence of Stranger Ratings of Personality and Intelligence With Self-Ratings, Partner Ratings, and Measured Intelligence". In: Journal of Personality and Social Psychology 65.3, pp. 546-553. ISSN: 00223514. DOI: 10.1037/0022-3514.65.3.546.

Braha, Dan and Marcus A.M. De Aguiar (May 2017). "Voting contagion: Modeling and analysis of a century of U.S. presidential elections". In: PLoS ONE 12.5. ISSN: 19326203. DOI: 10.1371/journal.pone. 0177970.

Claessens, Scott et al. (Apr. 2020). "The Dual Evolutionary Foundations of Political Ideology". In: Nature Human Behaviour 4.4, pp. 336-345. ISSN: 23973374. DOI: 10.1038/s41562-020-0850-9. URL: https://doi.org/10. 1038/s41562-020-0850-9.

Coleman, Stephen (Nov. 2018). "The Spatial Diffusion of Social Conformity in the United States and Russia: The Case of Voting Participation”. In: SSRN Electronic Journal. ISSN: 1556-5068. DOI: 10 . 2139 /ssrn . 3284794. URL: https: //papers. ssrn. com/abstract=3284794.

Cornelis, Ilse and Alain Van Hiel (Dec. 2015). "Extreme-Right Voting in Western Europe: The Role of Social-Cultural and Antiegalitarian Attitudes". In: Political Psychology 36.6, pp. 749-760. ISSN: 14679221. DOI: 10.1111/pops. 12187. URL: https : //onlinelibrary . wiley . com/doi/full/10 .1111/ pops. 12187.

Duckitt, John and Chris G. Sibley (Apr. 2009). "A Dual-process Motivational Model of Ideology, Politics, and Prejudice". In: Psychological Inquiry 20.23, pp. 98-109. ISSN: 1047840X. DOI: 10 . $1080 / 10478400903028540$. URL: https://www.tandfonline.com/doi/abs/10.1080/10478400903028540.

Dunleavy, Patrick (1980). "The Political Implications of Sectoral Cleavages and the Growth of State Employment: Part 1, the Analysis of Production Cleavages". In: Political Studies 28.3, pp. 364-383. DOI: $10.1111 /$ j . $1467-$ 9248 . 1980 . tb00475 . x. URL: https : / / doi . org/10 . $1111 / \mathrm{j} \cdot 1467$ 9248.1980.tb00475.x.

- (July 2005). "Facing Up To Multi-Party Politics: How Partisan Dealignment and PR Voting Have Fundamentally Changed Britain's Party Systems". In: Parliamentary Affairs 58.3, pp. 503-532. ISSN: 00312290. DOI: 10.1093/ pa/gsi049. URL: https://academic. oup.com/pa/article/58/3/503/ 1448004. 
Evans, Geoffrey, Anthony Heath, and Mansur Lalljee (Mar. 1996). "Measuring Left-Right and Libertarian-Authoritarian Values in the British Electorate". In: The British Journal of Sociology 47.1, p. 93. ISSN: 00071315. DOI: 10 . 2307/591118.

Gerber, Alan S. et al. (2011). "The Big Five Personality Traits in the Political Arena". In: Annual Review of Political Science 14.1, pp. 265-287. DOI: 10. 1146/annurev-polisci-051010-111659. URL: https : // doi . org/10 . 1146/annurev-polisci-051010-111659.

Golec de Zavala, Agnieszka, Rita Guerra, and Cláudia Simão (2017). "The Relationship between the Brexit Vote and Individual Predictors of Prejudice: Collective Narcissism, Right Wing Authoritarianism, Social Dominance Orientation". In: Frontiers in Psychology 8.2023. ISSN: 1664-1078. DOI: 10 . 3389/fpsyg. 2017.02023. URL: https://www.frontiersin.org/article/ 10.3389/fpsyg. 2017.02023.

Gosling, Samuel D., Peter J. Rentfrow, and William B. Swann (2003). "A Very Brief Measure of the Big-Five Personality Domains". In: Journal of Research in Personality 37.6, pp. 504-528. ISSN: 00926566. DOI: 10 .1016/S00926566 (03) 00046-1. URL: https://psycnet .apa.org/record/2003-09807003.

Greaves, Lara M, Andrew Robertson, and Lucy J Cowie (2017). "Predicting Party Vote Sentiment: Identifying the Demographic and Psychological Correlates of Party Preference in Two Large Datasets". In: New Zealand Journal of Psychology 46.3.

Hanretty, Chris (2017). "Areal Interpolation and the UK's Referendum on EU Membership". In: Journal of Elections, Public Opinion and Parties 27.4, pp. 466-483. DOI: $\backslash u r l\{10.1080 / 17457289.2017 .1287081\}$.

Harrop, Martin, Anthony Heath, and Stan Openshaw (1991). "Does Neighbourhood Influence Voting Behaviour - and Why?" In: British Elections and Parties Yearbook 1.1, pp. 101-120. ISSN: 0968-2481. DOI: $10.1080 /$ 13689889108412897.

Heath, Anthony and Omar Khan (Feb. 2012). Ethnic Minority British Election Study - Key Findings. Tech. rep. Runnymede Trust.

Henrich, Joseph, Steven J. Heine, and Ara Norenzayan (2010). "The Weirdest People in the World?" In: Behavioral and Brain Sciences 33.2-3, pp. 61-83. DOI: $10.1017 / \mathrm{S} 0140525 X 0999152 \mathrm{X}$.

Ho, Arnold K. et al. (Oct. 2015). "The Nature of Social Dominance Orientation: Theorizing and Measuring Preferences for Intergroup Inequality Using the New SDO7 Scale". In: Journal of Personality and Social Psychology 109.6, pp. 1003-1028. ISSN: 00223514. DOI: 10.1037/pspi0000033.

Hoover, Joe and Morteza Dehghani (Aug. 2020). "The Big, the Bad, and the Ugly: Geographic Estimation with Flawed Psychological Data". In: Psychological Methods 25.4, pp. 412-429. DOI: \url\{10.1037/met0000240\}.

Jerrim, John et al. (2017). "What Happens When Econometrics and Psychometrics Collide? An Example Using the PISA Data". In: Economics of Education Review 61, pp. 51-58. ISSN: 02727757. DOI: \url\{https://doi.org/10. 1016/j.econedurev.2017.09.007\}. 
Johnston, Ron, Kelvyn Jones, et al. (May 2004). "Party Support and the Neighbourhood Effect: Spatial Polarisation of the British Electorate, 1991-2001". In: Political Geography 23.4, pp. 367-402. ISSN: 09626298. DOI: 10.1016/j . polgeo.2003.12.008.

Johnston, Ron, Carol Propper, Simon Burgess, et al. (2005). "Spatial Scale and the Neighbourhood Effect: Multinomial Models of Voting at Two Recent British General Elections". In: British Journal of Political Science 35.3, pp. 487-514. ISSN: 00071234. DOI: 10.1017/S0007123405000268. URL: https: //www.cambridge.org/core/journals/british-journal-of-politicalscience/article/spatial-scale-and-the-neighbourhood-effectmultinomial-models - of - voting - at - two-recent-british-generalelections/D679184CFD29776B9DD429059A85968C.

Johnston, Ron, Carol Propper, Rebecca Sarker, et al. (Dec. 2005). "Neighbourhood Social Capital and Neighbourhood Effects". In: Environment 83 Planning A: Economy and Space 37.8, pp. 1443-1459. ISSN: 0308518X. DOI: 10. 1068/a37222. URL: http://journals. sagepub.com/doi/10.1068/a37222.

Jokela, Markus (2009). "Personality Predicts Migration Within and Between U.S. states". In: Journal of Research in Personality 43.1, pp. 79-83. ISSN: 0092-6566. DOI: https ://doi .org/10.1016/j.jrp. 2008.09.005. URL: https://www.sciencedirect.com/science/article/pii/S0092656608001402.

Kleppest $\varnothing$, Thomas Haarklau et al. (Sept. 2019). "Correlations Between Social Dominance Orientation and Political Attitudes Reflect Common Genetic Underpinnings". In: Proceedings of the National Academy of Sciences 116.36, pp. 17741-17746. ISSN: 0027-8424. DOI: 10 . 1073/PNAS . 1818711116. URL: https : //www . pnas . org/content/116/36/17741\%20https : //www . pnas . org/content/116/36/17741. abstract.

Laustsen, Lasse, Michael Bang Petersen, and Casey A Klofstad (2015). "Vote Choice, Ideology, and Social Dominance Orientation Influence Preferences for Lower Pitched Voices in Political Candidates". In: Evolutionary Psychology 13.3, pp. 1-13. ISSN: 14747049. DOI: 10.1177/1474704915600576. URL: https://us . sagepub.com/en-us/nam/open-access-at-sage.

Macallister, I. et al. (2001). "Class Dealignment and the Neighbourhood Effect: Miller Revisited". In: British Journal of Political Science 31.1, pp. 41-59. ISSN: 00071234. DOI: 10.1017/S0007123401000035. URL: /core/journals/ british-journal-of-political-science/article/class-dealignmentand-the-neighbourhood-effect-miller-revisited/F39C598AA19190EC34D5629912FCE77D.

McDonnell, Adam and Chris Curtis (Dec. 2019). How Britain voted in the 2019 general election. Tech. rep. YouGov.

Miller, William L. (1977). Electoral dynamics in Britain since 1918 / William L. Miller. eng. London: Macmillan. ISBN: 0333214935.

- (1978). "Social Class and Party Choice in England: A New Analysis". In: British Journal of Political Science 8.3, pp. 257-284. ISSN: 1469-2112. DOI: 10.1017/S000712340000137X. URL: https://www. cambridge.org/core/ journals/british-journal-of-political-science/article/socialclass-and-party-choice-in-england-a-new-analysis/OD63FD944E679BB539660102A2DD1720. 
Motyl, Matt, J. P. Prims, and Ravi Iyer (May 2020). "How Ambient Cues Facilitate Political Segregation". In: Personality and Social Psychology Bulletin 46.5, pp. 723-737. ISSN: 15527433 . DOI: $10.1177 / 0146167219875141$.

Mutz, Diana C. (May 2018). "Status Threat, not Economic Hardship, Explains the 2016 Presidential Vote". In: Proceedings of the National Academy of Sciences of the United States of America 115.19, E4330-E4339. ISSN: 10916490. DOI: $10.1073 /$ pnas.1718155115. URL: https://www.pnas.org/content/ 115/19/E4330.

Obschonka, Martin et al. (2018). "In the Shadow of Coal: How Large-scale Industries Contributed to Present-day Regional Differences in Personality and Well-being. Journal of Personality and Social Psychology". In: Journal of Personality and Social Psychology 115.5, pp. 903-927. DOI: \url\{10 . $1037 /$ pspp0000175\}.

Oishi, Shigehiro, Florian Kohlbacher, and Hyewon Choi (2018). "Does A Major Earthquake Change Attitudes and Well-Being Judgments? A Natural Experiment". In: Social Psychological and Personality Science 9.3, pp. 364371. DOI: 10.1177/1948550617707016. URL: https://doi.org/10.1177/ 1948550617707016.

Olivas Osuna, José Javier, Max Kiefel, and Kira Gartzou Katsouyanni (July 2021). "Place matters: Analyzing the roots of political distrust and Brexit narratives at a local level". In: Governance 34.4, pp. 1019-1038. DOI: https : //doi.org/10.1111/gove.12545.

Pratto, Felicia et al. (1994). "Social Dominance Orientation: A Personality Variable Predicting Social and Political Attitudes". In: Journal of Personality and Social Psychology 67.4, pp. 741-763. ISSN: 00223514. DOI: 10.1037/ 0022-3514 . 67 . 4 .741. URL: https : / / dash . harvard . edu/handle/1/ 3207711.

Przeworski, Adam and Glaucio A. D. Soares (Mar. 1971). "Theories in Search of a Curve: A Contextual Interpretation of Left Vote". In: American Political Science Review 65.1, pp. 51-68. ISSN: 0003-0554. DOI: 10 . 2307 / 1955043. URL: https://www . cambridge.org/core/journals/americanpolitical-science-review/article/abs/theories-in-search-of-acurve-a-\%09contextual-interpretation-of-left-vote/833F44355482FBAECBC0C3E293F1DE2C.

Putnam, Robert D (2001). Bowling Alone: the Collapse and Revival of American Community. eng. 1st Touchstone ed. New York ; London: Simon \& Schuster. ISBN: 0684832836.

R Core Team (2020). R: A Language and Environment for Statistical Computing. R Foundation for Statistical Computing. Vienna, Austria.

Rentfrow, Peter J (2020). "Geographical Psychology". In: Current Opinion in Psychology 32. Socio-Ecological Psychology, pp. 165-170. ISSN: 2352-250X. DOI: https: //doi.org/10.1016/j . copsyc. 2019.09.009. URL: https : //www.sciencedirect.com/science/article/pii/S2352250X19301733.

Rentfrow, Peter J., Markus Jokela, and Michael E. Lamb (Mar. 2015). "Regional Personality Differences in Great Britain". In: PLOS ONE 10, pp. 1-20. DOI: $\operatorname{lurl}\{10.1371 /$ journal.pone.0122245\}. 
Rosenbaum, Martin (Feb. 2017). Local Voting Figures Shed New Light on EU Referendum.

Salim Saib, Mahdi (2017). "Spatial Autocorrelation in Voting Turnout". In: Journal of Biometrics \& Biostatistics 08.05. ISSN: 2155-6180. DOI: 10.4172/ $2155-6180.1000376$.

Satherley, Nicole, Chris G. Sibley, and Danny Osborne (Aug. 2021). "Ideology Before Party: Social Dominance Orientation and Right-wing Authoritarianism Temporally Precede Political Party Support". In: British Journal of Social Psychology 60.2, pp. 509-523. ISSN: 20448309. DOI: 10.1111/bjso. 12414. URL: https : / / onlinelibrary . wiley . com/doi / abs / 10 . 1111/ bjso. 12414.

Schelling, Thomas C. (1971). "Dynamic models of segregation". In: The Journal of Mathematical Sociology 1.2, pp. 143-186. DOI: 10.1080/0022250X.1971. 9989794.

Sibley, Chris and John Duckitt (Sept. 2009). "Big-five personality, social worldviews, and ideological attitudes: Further tests of a dual process cognitivemotivational model". In: Journal of Social Psychology 149.5, pp. 545-561. ISSN: 00224545. DOI: 10 . 1080/00224540903232308. URL: https : / / ww . tandfonline.com/action/journalInformation? journalCode=vsoc20.

Solon, Gary, Steven J. Haider, and Jeffrey M. Wooldridge (2015). "What Are We Weighting For?" In: The Journal of Human Resources 50.2, pp. 301-316. ISSN: 0022166X.

Upton, G. J.G. and S J Stray (July 1986). "The Effect of the Environment on Party Identification". In: Environment \& Planning A: Economy and Space 18.10, pp. 1391-1400. ISSN: 0308-518X. DOI: 10.1068/a181391. URL: https : //journals.sagepub.com/doi/abs/10.1068/a181391.

Van Hiel, Alain and Ivan Mervielde (2002). "Explaining Conservative Beliefs and Political Preferences: A Comparison of Social Dominance Orientation and Authoritarianism". In: Journal of Applied Social Psychology 32.5, pp. 965976. ISSN: 00219029. DOI: $10.1111 / \mathrm{j} .1559-1816.2002$.tb00250 x. URL: /record/2002-17948-004.

Zmigrod, Leor et al. (2021). "The cognitive and perceptual correlates of ideological attitudes: a data-driven approach". In: Philosophical Transactions of the Royal Society B: Biological Sciences 376.1822, p. 20200424. DOI: 10. $1098 /$ rstb. 2020.0424.

\section{A Data Availability Statement}

The data, replication instructions, and the data's codebook will be made available upon publication. 


\section{B Supplementary Material}

Further supplementary materials, including the preregistration form and full regression tables, are available on Cambridge platform at XXXXX, and the Open Science Framework at https://osf .io/n7tjg/?view_only=d97ea0f01bac472b96a4895bf62cab43.

\section{Competing Interests}

The authors declare none.

\section{Acknowledgements}

The authors would like to thank Proffessor Mark Haggard (University of Cambridge) for his expertise on quantitative methods, Dr Amy Orben (University of Cambridge) for her insights on robust and replicable methodologies, and Dr Jennifer Sheehy-Skeffington (LSE) for preliminary review. 